\title{
Specific radiological findings, if present, can offer high accuracy for the differentiation of Xanthogranulomatous cholecystitis and gallbladder cancer
}

\author{
Hideki Suzuki \\ Department of Hepatobiliary and Pancreatic Surgery, Isesaki Municipal Hospital, Gunma, Japan \\ Correspondence to: Hideki Suzuki, MD. Department of Surgery, Isesaki Municipal Hospital, Gunma, 12-1 Tsunatori-honmachi, Isesaki 372-0817, \\ Japan. Email: hidesuzuki044@gmail.com. \\ Provenance and Peer Review: This article was commissioned by the editorial office, Annals of Translational Medicine. The article did not undergo \\ external peer review. \\ Comment on: Bo X, Chen E, Wang J, et al. Diagnostic accuracy of imaging modalities in differentiating xanthogranulomatous cholecystitis from \\ gallbladder cancer. Ann Transl Med 2019;7:627.
}

Submitted Feb 13, 2020. Accepted for publication Mar 09, 2020.

doi: 10.21037/atm.2020.03.193

View this article at: http://dx.doi.org/10.21037/atm.2020.03.193

Xanthogranulomatous cholecystitis (XGC) is rare form of chronic cholecystitis that is marked by a focal or diffuse destructive inflammatory process. The pathophysiology behind XGC is speculated to be the result of the extravasation of bile into the gallbladder (GB) wall through the vulnerable region such as Rokitansky-Aschoff sinuses or a small ulceration in the mucosa due to an increase of the inner pressure of biliary tract (1). Penetration of bile into the GB wall is generally attributed to the inflammation of intestinal tissue. Prolonged and more intensive infiltration by inflammatory cells turn acute inflammation into chronic inflammation and different amounts of fibrous tissue, inflammatory cells, and lipid-filled macrophages are appeared within the wall of the GB. XGC regions present themselves as yellow masses (2). This inflammatory process is often spreading to adjacent organs and is continuing for a long period. These inflammatory response result in strong adhesions, forming tumor like mass around the GB. Therefore, it is often difficult to differentiate between XGC and malignant GB lesions.

\section{Clinical, laboratory test features}

Patients with XGC showed symptoms similar to those of patients with acute or chronic cholecystitis. Signs and symptoms may include: features of acute cholecystitis, chronic cholecystitis, pain, obstructive jaundice, cholangitis, and palpable mass. It is also dilemma to differentiate XGC from other GB problems by laboratory tests. Yu et al. found that tumor markers are frequently elevated in XGC, which leads to bother surgeon for differentiating the disease from carcinoma of the GB (3). Therefore, CA199 cannot help surgeons determine the difference between $\mathrm{XGC}$ and malignant tumors. However, an explanation for the elevated CA19-9 level is that epithelial cells of the GB wall and bile duct have been injured due to inflammatory conditions. Subsequently, the production of CA19-9 in the epithelium increased, becoming very high, especially in obstructive disease. Mann et al. showed a relationship between elevated bilirubin and CA19-9 levels (4). If the level of bilirubin decreased, the level of CA19-9 would also decrease.

\section{Radiological findings}

Radiological findings are also nonspecific and similar to other forms of cholecystitis and GB carcinoma. However, some recent reports have shown that specific radiological findings, if present, are highly accurate in differentiating between XGC and GB cancer. In my opinion, if contrastenhanced ultrasound (CEUS) was performed by an experienced sonographer, the combination findings which are characteristic to XGC on CEUS and CT are the better way to distinguish XGC from GBC. 


\section{Ultrasonography}

Sonogram demonstrates the presence of gallstones or sludge as well as focal or diffuse thickening of the GB wall that is moderate to marked. Kim et al. reported observing intramural hypoechoic nodules on sonography in $73 \%$ of cases. They also indicated that, when both diffuse wall thickenings and intramural nodules formation are seen ultrasonographically, there is a strong possibility of XGC (5). Yamamoto et al. reported that measuring the GB wall blood flow (GWBF) and both resistance index (RI) and pulsatility index (PI), showing vascular resistance by color Doppler US, also helped differentiate between XGC and GBC (6). They speculated that vascular resistance would increase due to hard tissue around the vessels in advanced GB cancer.

\section{Endoscopic ultrasound (EUS)/EUS-guided fine-needle aspiration (FNA)}

EUS FNA is a useful modality for sampling various targets and collecting sufficient tissue specimens to facilitate accurate histological evaluation. However, a negative sample does not necessarily imply benign, due to the possibility of sampling from non-representative areas. Japan has accumulated cutting-edge technology in areas of endoscopic ultrasound-guided fine needle. Hijioka et al. reported that the accuracy of EUS FNA was $93.3 \%$ for detecting malignancy and $80 \%$ for final diagnosis (7).

\section{Computed tomography (CT)}

CT findings include diffuse or focal wall thickening, intramural hypoattenuating nodules in thickened walls, a continuous mucosal line, intra-mural hypo-attenuated nodules, and the absence of macroscopic hepatic invasion (8). Diffuse GB wall thickening was seen in $91 \%$ and $87.8 \%$ of patients with XGC by two separate researchers $(8,9)$. Gall bladder wall thickening in XGC is more commonly diffuse than focal and focal thickening is more likely to be related to carcinoma of the GB. Luminal surface enhancement of the GB wall indicated that the luminal epithelial layer would be preserved. Such findings might make it easier for the physician to differentiate XGC from GB cancer. Certain characteristic findings of CT could provide excellent accuracy for making diagnoses between XGC and GBC. Goshima et al. reported that meeting the three features out of five CT findings that are characteristic of XGC can present high accuracy for differentiating XGC from
GB cancer, and their sensitivity, specificity, and accuracy were $83 \%, 100 \%$, and $91 \%$, respectively (10). Uchiyama et al. retrospectively analyzed 32 patients with XGC. They indicated that, in patients of chronic GB disease with GB stones, CT findings of the enhanced continuous mucosal line in the thickened GB wall are more likely to indicate XGC (11).

\section{Magnetic resonance imaging}

Magnetic resonance imaging (MRI) criteria such as nonfocal wall thickening, type I enhancement, THAD (transient hepatic attenuation difference), and the presence of intramural nodules have also been described as helpful for making a differential diagnosis of XGC as opposed to GB carcinoma. Areas of iso- to hyperintense signals in T2-weighted images correspond to areas of significant xanthogranulomas (12). Currently, diffusion-weighted magnetic resonance imaging (DWI) is becoming popular due to its ability to differentiate malignant and benign lesions based on the assumption that malignant lesions generally display higher cellularity. Ogawa et al. showed that the positive signal rate with DWI was significantly higher in GB cancer (78\%) than in benign GB diseases (22\%) (13).

\section{Positron emission tomography}

Fluorine-18 fluorodeoxyglucose positron emission tomography (FDG-PET) could discriminate accurately between malignant and benign, and detect malignant change in benign neoplasms. However, FDG can accumulate in inflammatory lesions with the increase rate of glucose uptake, and FDG-PET is not specific for malignant lesions. Therefore, it is important to understand the diagnostic value of FDG-PET combined with other imaging modalities.

\section{Conclusions}

When it comes to the treatment of XGC, we should be more than skeptical about diagnosing XGC and suspect the presence of GB cancer. If patients display characteristic findings of XGC during preoperative evaluation, we need to perform fine-needle aspiration cytology of the GC preoperatively (14). Moreover, intraoperative frozen section biopsies may play an important role. In addition to the application of intraoperative frozen section examination, a combination of clinical and radiological factors can aid 
in diagnosis and surgery for XGC. We should judge it in a comprehensive manner. However, the interpretation of intraoperative biopsies may not always be straightforward. Since GB carcinoma and XGC may coexist, radical resection is justified when malignancy cannot be completely ruled out.

\section{Acknowledgments}

Funding: None.

\section{Footnote}

Conflicts of Interest: The author has completed the ICMJE uniform disclosure form (available at http://dx.doi. org/10.21037/atm.2020.03.193). The author has no conflicts of interest to declare.

Ethical Statement: The author is accountable for all aspects of the work in ensuring that questions related to the accuracy or integrity of any part of the work are appropriately investigated and resolved.

Open Access Statement: This is an Open Access article distributed in accordance with the Creative Commons Attribution-NonCommercial-NoDerivs 4.0 International License (CC BY-NC-ND 4.0), which permits the noncommercial replication and distribution of the article with the strict proviso that no changes or edits are made and the original work is properly cited (including links to both the formal publication through the relevant DOI and the license). See: https://creativecommons.org/licenses/by-nc-nd/4.0/.

\section{References}

1. Roberts KM, Parsons MA. Xanthogranulomatous cholecystitis: clinicopathological study of 13 cases. J Clin Pathol 1987;40:412-7.

2. Kwon AH, Matsui $Y$, Uemura Y. Surgical procedures and histopathologic findings for patients with xanthogranulomatous cholecystitis. J Am Coll Surg 2004;199:204-10.

3. Yu H, Yu TN, Cai XJ. Tumor biomarkers: help or mislead in the diagnosis of xanthogranulomatous cholecystitis?analysis of serum CA 19-9, carcinoembryonic antigen, and CA 12-5. Chin Med J (Engl) 2013;126:3044-7.

4. Mann DV, Edwards R, Ho S, Lau WY, Glazer G.
Elevated tumour marker CA19-9: clinical interpretation and influence of obstructive jaundice. Eur J Surg Oncol 2000;26:474-9.

5. Kim PN, Ha HK, Kim YH, et al. US findings of xanthogranulomatous cholecystitis. Clin Radiol 1998;53:290-2.

6. Yamamoto T, Horiguchi A, Ishihara S, et al. Multi-detector Row CT and Gallbladder Wall Blood Flow by Color Doppler US as a Useful Tool for Pre-operative Diagnosis in 3 Cases of Xanthogranulomatous Cholecystitis. Jpn J Gastroenterol Surg 2011;9:1126-33.

7. Hijioka S, Mekky MA, Bhatia V, et al. Can EUSguided FNA distinguish between gallbladder cancer and xanthogranulomatous cholecystitis? Gastrointest Endosc 2010;72:622-7.

8. Chun KA, Ha HK, Yu ES, et al. Xanthogranulomatous cholecystitis: CT features with emphasis on differentiation from gallbladder carcinoma. Radiology 1997;203:93-7.

9. Zhao F, Lu PX, Yan SX, et al. CT and MR features of xanthogranulomatous cholecystitis: an analysis of consecutive 49 cases. Eur J Radiol 2013;82:1391-7.

10. Goshima S, Chang S, Wang JH, et al.

Xanthogranulomatous cholecystitis: diagnostic performance of CT to differentiate from gallbladder cancer. Eur J Radiol 2010;74:e79-83.

11. Uchiyama K, Ozawa S, Ueno M, et al. Xanthogranulomatous cholecystitis: the use of preoperative CT findings to differentiate it from gallbladder carcinoma. J Hepatobiliary Pancreat Surg 2009;16:333-8.

12. Shuto R, Kiyosue H, Komatsu E, et al. CT and MR imaging findings of xanthogranulomatous cholecystitis: correlation with pathologic findings. Eur Radiol 2004;14:440-6.

13. Ogawa T, Horaguchi J, Fujita N, et al. High b-value diffusion-weighted magnetic resonance imaging for gallbladder lesions: differentiation between benignity and malignancy. J Gastroenterol 2012;47:1352-60.

14. Krishnani N, Shukla S, Jain M, et al. Fine needle aspiration cytology in xanthogranulomatous cholecystitis, gallbladder adenocarcinoma and coexistent lesions. Acta Cytol 2000;44:508-14.

Cite this article as: Suzuki H. Specific radiological findings, if present, can offer high accuracy for the differentiation of Xanthogranulomatous cholecystitis and gallbladder cancer. Ann Transl Med 2020;8(11):662. doi: 10.21037/atm.2020.03.193 